\title{
Mal-estar da democracia no Brasil e na Argentina nos anos 90: lutas sociais e crise de legitimidade das instituições democráticas ${ }^{1}$
}

\author{
Eliel Ribeiro Machado \\ Professor da Universidade Estadual de Londrina e \\ membro do NEILS - Núcleo de Estudos de Ideologias e Lutas Sociais.
}

E-mail: elielmac@uol.com.br

\section{Resumo}

Faremos uma incursão teórica acerca das relações entre lutas sociais, políticas de Estado e regime político. Consideramos que esta perspectiva de análise favorece um duplo exame. Por um lado, das limitações estruturais das democracias brasileira e argentina. E, por outro, das potencialidades de novas "invenções democráticas" presentes nas demandas e nas formas de organização de determinados movimentos sociais através de suas lutas.

Palavras-chave: lutas sociais; democracia brasileira; democracia argentina.

tema proposto é pertinente por permitir pensarmos o conceito de democracia a partir dos arranjos políticos ocorridos no Brasil e na Argentina nos anos 90 . Assim, sob processos eleitorais, observamos a implementação de políticas antipopulares que permitem a acumulação de capital de forma acelerada.

É importante ressaltar que esses países, a despeito de todas as diferenças históricas, sociais, políticas, culturais e econômicas, são capitalistas dependentes. Os novos arranjos políticos dos anos 80 - aquilo que

\footnotetext{
1 Este artigo tem um caráter meramente introdutório, por fazer parte de uma pesquisa de doutorado que está apenas iniciando. Nesse sentido, ele aponta algumas questões teóricas que serão aprofundadas no decorrer da pesquisa e do trabalho de campo.
} 
se convencionou chamar de "democratização" - deverão ser analisados sob essa perspectiva, até porque as "democracias"2 aqui instauradas serão substancialmente diferentes da países desenvolvidos. Em outras palavras: a "democratização" na América Latina veio no bojo da vitória política neoliberal. É bom lembrar que o processo que determinará a hegemonia do programa neoliberal não se realizou de uma hora para outra: "levou mais ou menos uma década, os anos 70, quando a maioria dos governos da OCDE - Organização Européia para o Comércio e Desenvolvimento - tratava de aplicar remédios keynesianos às crises econômicas. Mas, ao final da década, em 1979, surgiu a oportunidade. Na Inglaterra, foi eleito o governo Thatcher, o primeiro regime de um país de capitalismo avançado, publicamente empenhado em pôr em prática o programa neoliberal. Um ano depois, em 1980, Reagan chegou à presidência dos Estados Unidos. Em 1982, Khol derrotou o regime social liberal de Helmut Schimidt, na Alemanha. Em 1983, a Dinamarca, "Estado modelo do bem-estar escandinavo, caiu sob o controle de uma coalizão clara de direita, o governo de Schluter. Em seguida, quase todos os países do norte da Europa ocidental, com exceção da Suécia e Áustria, também viraram à direita. A partir daí, a onda de direitização desses anos tinha um fundo político para além da crise econômica do período" (Anderson, 1995, p.11).

Os governos civis eleitos ou não do início da década de 80, no Brasil e na Argentina, estão inseridos nesse contexto político importante: o neoliberalismo como uma força política e ideológica disputando a hegemonia da luta de classes dentro do aparelho de Estado. As atuações de Raúl Afonsin na Argentina e de José Sarney no Brasil, ora atendendo aos ditames neoliberais soprados pelo FMI e pelo Banco Mundial, ora repudiandoos, demonstram bem o conflito das classes e frações de classes com interesses contraditórios dentro do aparelho de Estado. O capital financeiro internacional, protagonista desse processo, busca incessantemente aliados locais para as suas empreitadas e, como veremos, consegue-os.

É justamente nesse período que nos deparamos com aquilo que Huntington denominará de "terceira onda" de democratização. Se pensar-

\footnotetext{
${ }^{2}$ Utilizamos o conceito entre aspas porque ao longo da nossa abordagem notaremos que há sérias dúvidas se os países latino-americanos se tornaram democracias após a retirada dos regimes militares. Como veremos, há intelectuais que afirmarão que. na verdade, se trata de um novo autoritarismo, embora legitimado por eleições.
} 
mos que a Europa (Inglaterra, França, Itália, Alemanha) do pós-guerra recebeu forte apoio financeiro dos Estados Unidos - através do Plano Marshall -, para sua reconstrução, fator que combina com a democratização nos países dominados pelo nazi-fascismo derrotado, na América Latina o processo é bem diferente: a democratização estava aliada à cobrança de sua dívida externa e a uma drástica redução de investimentos na região. ${ }^{3}$ As ditaduras militares latino-americanas deixaram os estados locais falidos e, ainda assim, o FMI exigiu o pagamento da dívida externa. ${ }^{4}$

Com o sucesso da hegemonia neoliberal na América Latina, as mudanças na políticas de Estado serão visíveis: "em primeiro lugar, controle da inflação por meio da adoção de uma drástica política de austeridade fiscal, endurecimento da política monetária e creditícia e redução dos salários; em segundo lugar, a maior privatização possível do setor público, sobretudo das suas companhias mais rentáveis, aceitando que estas fossem parar nas mãos do capital estrangeiro" (Harnecker, 2000).

Isso deve ficar claro, pois será a determinante para delimitarmos que tipo de "democracia" teremos na região, em especial na Argentina e no Brasil. Conforme nos aponta Antognazzi, podemos nos deparar com um falso dilema, ao contrapormos “ditadura militar” à "democracia”, uma vez que isso "escamotea el peso del poder financiero, esconde al enemigo de clase, limita la posibilidad de usar espacios que esta democracia aún admite, y es usada por el 'discurso oficial' como justificación de las polí-

\footnotetext{
${ }^{3}$ Apenas para termos uma idéia: “com o início da 'crise da dívida', em 1982, o volume de empréstimos bancários à região foi drasticamente reduzido, embora no decorrer da década - de 1983 a 1989 - a dívida externa acumulada na região cresceu de 257 bilhões para 452 bilhões de dólares, apesar de pagamentos de juros que totalizaram 170 bilhões, resultando numa drenagem de recursos tão vultosa (US\$ 120 bilhões) que o então presidente do Banco Mundial viu-se impelido a comentar, com certa hesitação, que 'a transferência de recursos de tais dimensões é... provavelmente prematura'” (Petras, 2000).

+ Segundo Harnecker, a manipulação das taxas de juros pelos bancos internacionais "promoveu um êxodo de capitais latino-americanos para os países europeus e, sobretudo, para os Estados Unidos, o que contribuiu para agravar a situação financeira dos nossos países. (...) Esta situação criou uma bomba-relógio financeira que rebentou em 1982, quando eclodiu a primeira grande crise econômica mexicana e este país não pôde pagar a sua dívida externa. Criou-se assim o cenário para o segundo ato do drama: a entrada em cena das instituições financeiras internacionais, encabeçadas pelo Fundo Monetário Internacional" (Harnecker, 2000).
} 
ticas actuales para mantener o consenso expresado por vía electoral" (Antognazzi, 2000,p.148). A autora nos chama a atenção para o fato de que a "democracia" argentina será aquela favorável aos interesses do grande capital financeiro: "un Poder Judicial con poco margen para la 'independencia' del Gobierno y del poder del Estado; un Congreso Nacional 'estable', más bien una oficina de lobbistas, para producir las leyes que requieren los intereses transnacionales; un mecanismo electoral ajustado a cronogramas rigurosos y cómputos eletrónicos, pero vaciado de contenidos y basado en consignas cada vez más alejadas de expresar programas de gobierno y debates políticos" (Antognazzi, 2000,p.144).

Os regimes eleitorais instaurados a partir da década de 80 serviram para legitimar as políticas antipopulares dos governos da região. A "democratização", portanto, significou apenas possibilidade de participação eleitoral, mas, questões determinantes das políticas de Estado não são submetidas ao sufrágio. Na verdade, os governos eleitos a partir dos anos 80 terão como prioridade o pagamento das suas dívidas externas. ${ }^{6}$

De forma sumária, a vitória do projeto neoliberal (o chamado "ajuste") trouxe consequiências drásticas para o Brasil e para a Argentina, principalmente para as classes populares. ${ }^{7} \mathrm{Um}$ dos indicadores que podemos

${ }^{5} \mathrm{O}$ problema é que a democracia não foi concebida para favorecer as expectativas das classes populares que compõem a maioria da população. Ao analisar a declaração de Joseph Nye, chefe do Conselho Nacional de Inteligência dos Estados Unidos, na qual ele afirma que o maior interesse dos Estados Unidos é prevenir o retrocesso da América Latina ao autoritarismo, Antognazzi afirma que "no se refiere solamente a los golpes militares sino al 'estatismo', las formas de Estado y de democracia que corresponden a la etapa de la hegemonía de la burguesía nacional y del Estadonación y, sobre todo, está tomando precauciones acerca da posibilidad de insurrecciones u outras formas de alzamientos populares". Tal tipo de democracia (chamada de "democracia de mercado") serve aos interesses políticos, econômicos e de segurança dos Estados Unidos, afirma Nye. Então, questiona Antognazzi: "qué es 'democracia de mercado' sino libertades para que hagan su juego los dueños de los grandes capitales mientras se recortan las libertades al pueblo?". Sendo assim, o caráter da democracia para as classes populares diferencia substancialmente dos grupos financeiros: "las recientes experiencias de masas de Colombia, Venezuela, Ecuador, Paraguay, dan muestras de que la 'estabilidad' que buscan los pueblos es de un carácter opuesto a la que imponen por la fuerza material y subjetiva los grupos financieros, quienes denuncian como atentados contra la democracia las protestas y alzamientos populares" (Antognazzi, 1999,p.141).

${ }^{6}$ Segundo Petras, a transferência líquiida de capital da América Latina para o Hemisfério Norte, na década de 80 , girou em torno de 280 bilhões de dólares (Petras, 1999) 
observar é o crescimento da taxa de desemprego, bem como a transferência de renda dos trabalhadores para as classes dominantes. Na Argentina, na região metropolitana de Buenos Aires, a taxa de desemprego total chegava a casa dos 12,2\% (1994), dos 17,3\% (1996) (Cano, 1999, p.149)e, em 1997, dos $17 \%$, sendo que, na região metropolitana da Grande Rosario, nesse mesmo ano, o índice era de 26,8\% (Scribano, 1999,p.53). Na região metropolitana de Bahia Blanca (província de Buenos Aires), em 1997, o índice era maior, $19,5 \%{ }^{8}$ No Brasil, tomando por base os mesmo anos, temos os seguintes dados da região metropolitana de São Paulo: 14,2\% (1994), 15,1\% (1996), 16\% (1997) e no ano de 1999, 19,3\% (SEADE, 2000).

Em relação à transferência de renda dos trabalhadores para a burguesia financeira, também temos vários exemplos no Brasil: "OBNDES decidiu financiar a maior parte das privatizações com recursos oriundos do Fundo de Amparo ao Trabalhador. Graças a esse financiamento (com desvio de finalidade e fraude à lei), a primeira medida administrativa dos novos controladores consistiu na dispensa coletiva de empregados. Foram extintas, só nas empresas telefônicas privatizadas, 18 mil vagas em pouco mais de seis meses" (Comparato, 1999). ${ }^{9}$

Nessa tentativa de assinalar algumas características importantes da "democratização" no Brasil e na Argentina, é preciso lembrar que as decisões econômicas (chamadas de "ajuste") e de segurança nacio-

.$^{7}$ Estamos entendendo aqui por classes populares aquilo que se convencionou chamar de "proletariado no sentido amplo", ou seja, o conjunto daqueles que não são proprietários dos meios de produção e, portanto, não estão inseridos diretamente no processo de produção industrial, segundo as relações de produção capitalistas. O "proletariado no sentido restrito" comporia o conjunto daqueles com inserção direta no processo de produção industrial (Przeworski, 1991,p.80-81).

${ }^{8}$ Não por acaso, a primeira reivindicação dos "cortes de ruta" na Argentina é por postos de trabalho (Scribano, 1999,p.62).

"Apenas para exemplificarmos um pouco mais: "No governo FHC, no entanto, a Caixa Econômica Federal (CEF) tem sido utilizada para aumentar os lucros dos bancos privados, vergonhosamente obrigada a 'engolir' bilhões e bilhões de prejuízos que, na prática, seriam dos banqueiros. Como? Na quebra do Banco Econômico, por exemplo, a CEF 'comprou' a carteira imobiliária, isto é, os contratos de financiamento da casa própria que o Econômico havia concedido. Valor: 1,7 bilhão de reais. Na quebra do Bamerindus, a mesma coisa. Até aí, a Caixa já estava sendo usada para 'engolir' negócios 'podres', com alto nível de inadimplência, ou empréstimos que nunca seriam pagos, de bancos que quebraram" (Biondi, 1999, p.31). 
nal desse período, não são tomadas pelos Parlamentos eleitos (Harnecker, 2000, p.214). Tanto Petras (1999), quanto Harnecker (2000) e Chossudovsky (1999) chamam a atenção para o fato de que tais decisões são tomadas por burocratas a milhares de quilômetros daqui, nos escritórios centrais das grandes instituições financeiras (FMI, Banco Mundial) ou até mesmo na Casa Branca.

Torna-se inviável discutir a democratização no Brasil e na Argentina nos anos 90 sem levar em conta esses fatores, pois estamos diante de um problema grave: a maioria dos argentinos e dos brasileiros não tem poder de decisão. $O$ pouco poder que lhes resta, restringe-se apenas à escolha dos governantes que serão coadjuvantes nas políticas impostas pelo FMI e pelo Banco Mundial. Não é à toa que figuras importantes do primeiro escalão do governo devem ter o aval externo: "O FMI decidira ser muito mais rígido com o novo governo: três ministros da Fazenda foram indicados durante os primeiros sete meses do governo Itamar Franco e nenhum deles foi amigavelmente endossado pelo FMI, que, nesse tempo, enviara seus auditores, para monitorar os progressos econômicos nos termos do acordo em vigor: as metas trimestrais para o déficit orçamentário não tinham sido atingidas (e não poderiam ser alcançadas sem emendas na Constituição)" (Chossudovsky, 1999, p.175).

A implantação do projeto neoliberal nos países de capitalismo dependente nos anos 80 e 90 variará de país para país. A correlação de forças aliadas e contrárias a ele é um fator considerável. De toda forma, o final dos anos 80 e início dos 90 parece propício à decolagem do projeto neoliberal, com a vitória de Menem na Argentina e de Collor no Brasil. Tudo indica que a correlação de forças favoráveis ao capital financeiro transnacional estava dada. Nesse sentido, nas eleições de 1989 na Argentina, Menem não teve grandes problemas para vencer as eleições, além de ter obtido vitórias provinciais importantes em 1991 que fortaleceram o seu governo (Cano, 1999, p.122). Entretanto, as promessas eleitorais não combinavam em nada com os resultados políticos do projeto neoliberal: aumento de salários e uma revolução produtiva com a abertura de fábricas (Quintar \& Argumedo, 2000, p.45). O receituário do FMI e do Banco Mundial foi aplicado com todo o rigor pelo governo de Carlos Menem. As privatizações ocorreram sob "escandalosa subavaliação das empresas e do patrimônio público estatal, [constituindo] um novo translado de recursos públicos para o capital es- 
trangeiro, associado com os setores monopólicos nacionais. Ao fortalecer esses setores e uma minoria privilegiada em detrimento do resto da sociedade, aprofundou-se o desenvolvimento fortemente polarizado que caracteriza grande parte das economias latino-americanas. E a liqüidação do aparato estatal completou a tarefa iniciada pelo ministro da economia da ditadura militar, Martinez de Hoz. Por sua vez, o projeto do ministro Cavallo possibilitou o ingresso da Argentina no Plano Brady, o qual lhe facilitaria a obtenção de créditos adicionais do sistema financeiro internacional, em troca do compromisso de implementar um novo ajuste sobre o setor público. Desta forma, garantia-se o equilíbrio fiscal, assim como o pagamento das taxas de juro e o capital da dívida externa, sob o controle do FMI e os bancos credores" (Quintar \& Argumedo, 2000, p.46).

No Brasil, o processo foi um pouco diferente. No bojo da crise deixada pelos militares e pelo PMDB, desgastado com o governo Sarney e com o fracasso dos sucessivos planos econômicos, principalmente o Cruzado, "Collor surge como 'salvador da pátria' para as elites conservadoras, para a desnorteada classe média e para a desinformada massa de miseráveis, dizendo que defenderia a modernidade e os 'descamisados' (de quem obteve a maioria dos votos), vociferando contra - entre outras - as 'elites', as multinacionais que fabricavam 'carroças em vez de automóveis' e os funcionários públicos 'inoperantes' e que ganhavam salários de marajá" (Cano, 1999, p.228).

O governo Collor enfrentará uma série de problemas e será afastado do cargo sob acusação de corrupção, o que lhe valeu durante o processo uma Comissão Parlamentar de Inquérito. Seu mandato se encerrou em setembro de 1992. Assume então o seu vice, Itamar Franco, que inicia o seu mandato sob uma inflação galopante, mas consegue estabilizar a moeda a partir de julho de 1994: "Quem colheu os melhores e maiores frutos políticos da estabilização foi seu ministro da Fazendo, Fernando Henrique Cardoso, que não só deu continuidade ao projeto neoliberal de Collor, mas o aprofundou. O Plano Real, programa de estabilização implantado a partir de dezembro 1993, parece ter sido um cronograma eleitoral perfeito. Com o sucesso inicial da estabilização econômica ocorrendo poucas semanas antes da eleição presidencial, foi o carro chefe da campanha de FHC'. (...) Nesse período, o país foi ainda mais bombardeado pelo discurso neoliberal, com a falsa promessa da ida ao Primeiro Mundo" (Cano, 1999, p.229-230). 
Voltando à nossa discussão sobre a tomada de decisões, podemos questionar em que medida as eleições têm servido para as classes populares disputarem a hegemonia política. Eleições periódicas, honestas, imparciais, liberdades políticas e de expressão, publicação, reunião e organização (Huntington, 1994, p.17) são critérios suficientes para assegurar se um país é democrático ou não?

Um outro problema: muitos intelectuais vêm-se posicionando contrários aos argumentos que sustentam que na América Latina há democracia. $\mathrm{O}$ conceito é tão adjetivado negativamente que chega a comprometê-lo. ${ }^{10}$ Huntington está na direção oposta: as democracias latino-americanas estão consolidadas (1994)."

Diante do exposto, faz-se necessário investigar os mecanismos políticos e ideológicos que legitimam as ações políticas antipopulares e autoritárias dos governos eleitos na década de 90 , bem como as reações das classes populares às decisões tomadas pelos órgãos que prescindem da legitimidade dos pleitos eleitorais, como o FMI e o Banco Mundial.

Como sabemos, uma das formas de aferirmos o grau de insatisfação das classes populares às democracias implantadas na região são as pesquisas de opinião pública. Elas acabam revelando o desgaste do regime ao longo do tempo e dos governos escolhidos nos pleitos eleitorais.

Segundo a Corporación Latinobarómetro (2000), apenas 37\% dos latino-americanos estão satisfeitos com a democracia. No Brasil, em particular, esse índice baixa para 17\% (1999/2000). É interessante notar que em 1998, ao lado do Equador e Paraguai, tal índice era de 27\%. Enquanto 39\% apóiam a democracia no Brasil, no Uruguai, Costa Rica e Argentina, esse índice é maior: 84,83 e $71 \%$, respectivamente. Evidentemente que apoio não significa satisfação. Se de um lado, $71 \%$ dos argentinos apóiam a democracia, por outro, somente $37 \%$ estão satisfeitos com ela. Considerando que tais índices são, no mínimo, preocupantes, devemos ter em conta que "oito

10 Vejamos alguns exemplos: "democracia autoritária" (Chossudovsky, 1999; Harnecker, 2000), "regimes eleitorais burgueses, novo autoritarismo" (Petras, 1999), "democracia restringida" (Quintar \& Argumedo, 2000; Harnecker, 2000), "democracia dos grupos financeiros transnacionais" (Antognazzi, 2000), "ditadura constitucional" (Dallari, 1998). Numa crítica mais branda: "democracias delegativas" (O'Donnell, 1986).

"Para Petras, a "democracia" está garantida enquanto a direita não se sentir ameaçada (Petras, 2000: 175). 
entre dez brasileiros acham ilegítimas as eleições de seu país. É um dado recorde do continente (...). Marta Lagos, coordenadora do Latinobarómetro em Santiago, explica que a reação da opinião pública não significa que se perceba fraude nas eleições, mas que estas estão desvirtuadas pelo poder econômico e pelo uso da máquina estatal" (Época, 23/05/98).

Como esta pesquisa tem dimensões continentais, abrangeu mais de 17 mil entrevistados, os problemas aferidos são variados. Apenas para efeito de ilustração, dentro da preocupação do desgaste da democracia na região, chama-nos a atenção o fato de que $67 \%$ dos argentinos crêem que as instituições com mais poder em seu país são as grandes empresas, enquanto na Venezuela e no Peru, 64 e 54\%, respectivamente, dizem ser os militares. Na América Latina, as instituições com mais poder, segundo esta pesquisa, são o governo (56\%), as grandes empresas (50\%), os partidos políticos (27\%), os militares (26\%) e os bancos (21\%). É importante notar que as grandes empresas têm quase o mesmo poder que os governos.

Também é mister observar as expectativas dos entrevistados em relação à economia do país: somente $39 \%$ dos argentinos apostam que a situação econômica futura será melhor. No Brasil, o índice é mais baixo, 19\%. Como os governos da região adotaram o receituário neoliberal e promoveram as maiores privatizações das empresas estatais, o instituto também procurou aferir o grau de aprovação dos entrevistados: em 1998, $48 \%$ dos argentinos estava em desacordo com elas e, em 1999/2000, esse índice subiu para $68 \%$. O mesmo pode-se dizer de outros países: Costa Rica (27\% em 1998 e 49\% em 1999/2000), Guatemala (36\% em 1998 e 63\% em 1999/2000) e Paraguai (36\% em 1998 e 59\% em 1999/2000). Os governos neoliberais prometeram, em suas campanhas eleitorais e depois através das publicidades oficiais, que com o "enxugamento" da máquina estatal, disporiam de mais recursos para investirem em saúde, educação e segurança. As privatizações ocorreram, sob suspeita de subavaliação das empresas estatais, e nem por isso os serviços básicos de saúde e educação tiveram melhora significativa.

Por fim, sabemos que, ao lado do desgaste do regime democrático, encontramos a queda de aprovação dos governos eleitos. No Brasil, o governo Cardoso é emblemático. Se no início do seu primeiro mandato o índice de aprovação chegava à casa dos $41 \%$ e o de rejeição em $25 \%$, em setembro de 1999, portanto, no segundo mandato de seu governo, o 
grau de rejeição atingia 56\% (Folha de S. Paulo, 31/12/95). Ao compararmos com o final do seu primeiro mandato em 98 , observamos que $o$ índice de rejeição é mais do que o dobro daquele período.

O governo Fernando De la Rúa, na Argentina, que se elegeu como opositor ao governo Carlos Menem, sofre forte desgaste popular. Numa pesquisa divulgada pelo jornal La Nación (18/06/00), 51\% dos entrevistados desaprovam o governo, contra apenas $33 \%$ que aprovam. Em março, o índice de desaprovação era de $29 \%$. Segundo tal pesquisa, enquanto $31 \%$ acredita que o governo está no "caminho correto", $52 \%$ considera que suas políticas de governo são "incorretas" (La Nación, 18/06/00). Não devemos menosprezar que o índice de aprovação ao governo já esteve na casa dos $71 \%$, em fevereiro de 2000 (Gazeta Mercantil, 11, 12 e 13/08/00).

A pesquisa de opinião, como sabemos, pode não ser o único meio de aferirmos a crise de legitimidade das democracias analisadas, mas, os seus resultados contribuem para entendermos melhor que há uma distância muito grande entre a aprovação eleitoral e, posteriormente, o exercício do governo, ou sua alteração capaz de manter e/ou ampliar a mesma base de apoio popular. Essa não é uma norma, mas não é desprezível que haja uma rejeição tão significativa aos governos eleitos.

Voltando à questão que estávamos analisando, dos critérios propostos por Huntington, somente o primeiro (eleições periódicas) é que parece funcionar na América Latina, mesmo assim repleto de casuísmos (a conquista do direito de reeleição de Menem e Cardoso até hoje permanece obscura). Os demais precisam ser observados com cuidado: tanto na Argentina quanto no Brasil, as eleições parecem carecer de honestidade e imparcialidade. Basta lembrarmos das relações subliminares de Menem com os grupos financeiros nacionais e transnacionais na Argentina (Quintar \& Argumedo, 2000; Antognazzi, 2000). Quanto ao Brasil, todos sabemos dos financiamentos da campanha eleitoral de Cardoso pelos grupos financeiros locais, bastando para isso consultar os próprios dados oficiais do Tribunal Superior Eleitoral. ${ }^{12}$ Como também sabemos das "ligações perigosas" entre Armínio Fraga (presidente do Banco Central do Brasil) e o megainvestidor Jorge Sorus, além das boas relações entre Pedro Malan e o Banco Mundial e FMI.

O projeto neoliberal procura maximizar a fragmentação social, com o objetivo de não permitir que as classes populares e suas frações 
de classe se organizem suficientemente para formar maioria e assim se contrapor à hegemonia política dominante. Tal fragmentação não permite o questionamento dessa hegemonia. Aliás, esse questionamento é feito isoladamente por grupos sociais que conseguem uma maior organização. Entretanto, "a base para manter estes grupos isolados entre si ou sujeitos a relações contraditórias é procurar conscientemente desorientá-los em relação aos seus possíveis objetivos comuns, impossibilitando que estas minorias assumam lutas coletivas" (Harnecker, 2000, p.211). Ao lado dessa fragmentação social, o projeto neoliberal procura "fabricar" o consenso, tendo como aliado, fortíssimo para isso, os meios de comunicação de massas. É interessante notar que esta verdadeira doutrinação política se realiza fora do campo e da linguagem política. A "fabricação do consenso" é feita pelo marketing político. Assim, os problemas financeiros, econômicos e administrativos atravessados pelo país passam a ser exclusivos da área técnica e não estão sujeitos ao debate político.

O problema que se coloca para as próprias classes dominantes é o de como legitimar o projeto neoliberal, uma vez que ele desserve aos interesses das classes populares. Como conseguir que os resultados econômicos do "modelo" neoliberal sejam compatíveis com as instituições democrático-burguesas? (Harnecker, 2000, p.214). Em outras palavras: "como manter o consenso político majoritário numa sociedade que, ao mesmo tempo, sente-se crescentemente ameaçada por estratégias econômicas que deterioram cada vez mais suas condições de vida [?]. Se nas ditaduras o consenso é substituído pela coação, a legitimidade requerida pelos governos constitucionais torna cada vez mais difícil a possibilidade de manter orientações socioeconômicas excludentes, sem que isso alimente comportamentos políticos e sociais que põem em questão o caráter democrático desses governos"(Quintar \& Argumedo, 2000, p.36).

\footnotetext{
12. Se quisermos pensar em termos de Brasil, os dados oficiais do Tribunal Superior Eleitoral não nos deixam enganar: nas eleições presidenciais de 1998, enquanto o candidato Fernando Henrique Cardoso teve uma ajuda financeira na casa dos $R \$$ 45 milhões, o seu principal opositor, Luís Inácio Lula da Silva (PT), não somou mais do que $R \$ 2,6$ milhões. Devemos atentar que nestas eleições, somente o Banco Itaú financiou R \$ 2,6 milhões para a campanha de Cardoso, ou seja, o mesmo valor de toda a arrecadação do candidato do PT.
} 
Os mais variados tipos de movimentos sociais latino-americanos parecem questionar exatamente o caráter democrático desses governos. De forma variada e diferenciando-se muito entre si, lutam para reverter o quadro social, político e econômico desfavorável aos seus interesses e favorável ao capital local e transnacioanal. Esses movimentos são fortemente reprimidos pelos governos eleitos, principalmente quando têm força política suficiente para resistir às políticas impostas pelo projeto neoliberal.

Os resultados dessa resistência podem ser vistos a olho nu: mortes, prisões, tortura, chantagem etc. Então, como podemos sustentar os outros critérios sugeridos por Huntington (liberdades políticas e de expressão, publicação, reunião e organização) quando o Movimento dos Trabalhadores Sem-Terra (MST) é criminalizado pelo governo sob a acusação de formação de quadrilha, quando seus militantes são mortos e torturados, ou quando se ressuscita a famigerada Lei de Segurança Nacional? De forma semelhante, podemos perguntar sobre a forte repressão contra os militantes políticos argentinos que participam das "puebladas" ou do MOCASE (Movimiento Campesino de Santiago del Estero)? Tudo leva a crer que ou os critérios são insuficientes ou não

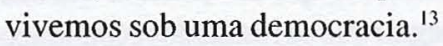

Na Argentina, há casos e mais casos de repressão violenta contra as "puebladas"14 ou outras formas de protesto popular. A violação

${ }^{13}$ Durante o transcurso de nossa pesquisa ampliaremos os dados sobre isso, mas no lermos o material de imprensa e os artigos produzidos sobre o assunto, deparamonos com títulos sugestivos do grau de repressão empreendido pelos governos Menem e Cardoso contra os movimentos sociais ("Chaco: violenta protesta", "Violência policial y orden público", "Reprimen a docentes que hacían huelga de hambre", "La historia de una madrugada cargada de furia y versiones", "Al denuncia la práctica sistemática de la tortura en Argentina", "Presos políticos de La Tablada en huelga de hambre", "Cronología de la violencia en Mosconi", "Argentina: El terror que están viviendo en el Movimiento Campesino de Santiago del Estero" etc. - fontes: El Clarín e Rebelión; no Brasil não é muito diferente: "Criminalização do MST", "Recrudescimento da barbárie", "Choque dos 500 anos deixa feridos e mais de 100 presos", "A luta pela terra e a violação dos direitos humanos no Paraná", "Violência no Paraná", "Violência continua no Paraná: mais um trabalhador espancado e dois ameaçados", "Trabalhador rural torturado", "Mais um trabalhador tomba na luta pela terra no Paraná," "Pistoleiros atiram em criança de 8 anos", "Chega de tolerar transgressão, diz FHC", "Sem-Terra são condenados pelas mortes de 2 policiais", "MST se prepara para enfrentar onda de prisões no Pontal" etc - fontes: Folha de S. Paulo, O Estado de S. Paulo, Home Page do MST). 
dos direitos constitucionais é uma constante: "Desde la Carpa Negra Campesina en La Simona, el día 12 de octubre de 1999, se volvió a desatar una hondonada de persecuciones, amenazas y actos contrarios a las garantías constitucionales" (Rebelión, 2000). Em um outro protesto, "fueron tres revueltas. General Mosconi y San Ramon de la Nueva Orán, ambas em Salta, y en San Pedro, Jujuy. Sólo en la primera murieron al menos 4 personas" (Rebelión, 2000). Vale a pena ressaltar que uma das características, em linhas gerais, das "puebladas" é que os partidos tradicionais e os sindicatos não integram suas formas de luta. Seus militantes não as aceitam (Laufer \& Spiguel, 1999; Scribano, 1999). Com isso, elas tendem a não reconhecer os ocupantes de cargos governamentais: "Integrantes del movimiento de desocupados General San Martín, que se encuentra acampado frente a la Casa de Gobierno de Chaco, atacaron ayer a pedradas esse edifício, en protesta por el atraso en el pago de los planes sociales para 170 jeves de familia que les habia prometido el Poder Ejecutivo" (El Clarín, 18/07/99). É igualmente importante destacar que a primeira reivindicação das "puebladas" é por posto de trabalho e podemos dizer que dado o grau de organização e mobilização popular que elas têm empreendido, o governo tem sido obrigado, a contragosto, a atender esta reivindicação: por exemplo, nas manifestações de Cutral Co y Plaza Huincul, os manifestantes conseguiram 1,8 mil contratos de trabalho temporários. Não sabemos ao certo quantos presos políticos existem na Argentina, entretanto, depois de 11 anos $(23 / 12 / 89)$ que sucederam os acontecimentos em La Tabalada, continuam encarcerados os seus militantes (Rebelión, 2000).

No Brasil, as investidas do governo Cardoso contra o MST deixam um saldo lamentável de mortes, prisões, ameaças de morte, tentati-

\footnotetext{
14 As "puebladas" seriam "rebeliones urbanas desatadas en localidades del interior del país, algunas de las cuales se proyectaron a escala provincial (caso de Libertador/ Jujuy). Este fenómeno debe ser enfocado com parte y experiencia más destacada de un movimiento social y político más amplio y polifacético, con diversos afluentes sociales, contenidos y formas de lucha: movimientos barriales y de desocupados, marchas sindicales y reclamos salariales, paros y 'tractorazos' agrarios, movimientos populares contra los abusos de los servicios privatizados, movimiento democrático muy amplio y activo contra la impunidad de los genocidas de la dictadura de 19761983 y de exigencia de justicia frente a la impune violencia policial y de sectores vinculados al poder político y económico (...)" (Laufer \& Spiguel, 1999: 30).
} 
vas de assassinatos, violação dos direitos humanos etc. ${ }^{15}$ Apenas para ilustrar, nos últimos 12 anos, foram assassinados 1167 trabalhadores(as) sem-terra e apenas 86 desses casos foram julgados e sete dos mandantes foram condenados. O número de trabalhadores assassinados cresceu em $56,67 \%$ de 1997 para 1998. Sendo que nesse último ano, 46 sofreram tentativas de assassinato, 88 foram ameaçados de morte, 35 torturados, 164 agredidos fisicamente, 466 presos e 207 sofreram lesões corporais. E mais, em 1999, 450 foram presos arbitrariamente. Dos estados brasileiros, o Paraná é o campeão de repressão ao MST: somente na década de 90, 251 trabalhadores(as) foram presos nesse estado, sendo que 209 prisões ocorreram no governo Lerner. Assassinatos, apenas em 1998, foram oito. Em 1999, foi assassinado um, somando 41, dos quais 27 foram na década de 90 . Além disso, ocorreram, na década de 90,49 tentativas de assassinatos, 55 ameaças de morte e mais de 250 militantes torturadas, vítimas de agressão, espancamentos etc. ${ }^{16}$

Um fato trágico e, ao mesmo tempo, exemplar disso que estamos falando, foi a investida do governo Lerner contra os sem-terra em Querência do Norte, Paraná, no dia 06 de maio de 1999. A cidade se transformou num verdadeiro campo de guerra, inclusive com a suspensão das garantias individuais (estado de sítio): "O efetivo deslocado para o cumprimento da reintegração de posse e criminalização dos trabalhadores é um verdadeiro contingente de guerra: carros com cachorros treinados para o ataque às multidões, helicóptero, grupo anti-sequiestro, mais de 100 viaturas, mais de 30 ônibus, policiais à paisana do Serviço especial (inclusive com carros civis e elementos com capuz, evitando identificação). Calcula-se que existem mais de 2000 homens participando da operação, com armamento específico para o controle da multidão (tropas de choque, bombas de gás).

15 Ao lado desse quadro, temos um outro: os maiores latifundiários do Brasil são: 1 . Manasa - Madeireira Nacional S/A, (4.140.767 ha); 2. Jari Florestal e Agropecuária Ltda (2.918.892 ha); 3. Aplub Agroflorestal da Amazônia (2.194.874 ha); 4. Companhia Florestal Monte Dourado (1.682.227 ha); 5. Companhia de Desenvolvimento do Piaú́ (1.076.752 ha); 6. Cotriguaçu - Colonizadora de Aripuanã (1.000.000 ha); 7. João Francisco Martins Barata (1.000.000 ha). Fonte: Eng. Agro. Carlos Lacerda a partir de dados do Incra.

${ }^{16}$ A principal fonte de informação utilizada aqui é o endereço do MST na internet (www.mst.org.br) que mantém um banco de dados juntamente com o Centro de Justiça Global e a CPT. 
Os despejos começaram às duas da manhã (...). Durante os despejos os acampamentos dos trabalhadores foram completamente destruídos, utensílios e objetos pessoais foram queimados e outros perdidos durante $o$ transporte dos trabalhadores. (...) O fato mais alarmante na efetuação das prisões arbitrárias foi a violência deliberada contra crianças das áreas despejadas. Os advogados da Rede Autônoma de Advogados Populares do Paraná (RENAAP) identificaram a detenção de 3 crianças e um adolescente (idades entre 10,13, 15 e 16 anos), dentro de uma toyota da polícia , cercados por um grande número de policiais" (MST/ CPT).

Apesar de todo esse aparato repressivo contra o MST, os trabalhadores sem-terra vêm conseguindo algumas vitórias importantes contra o projeto neoliberal. Evidentemente que a hegemonia de direita que está instalada no poder não está trincada, ainda apresenta fôlego, mas o movimento vem questionando as políticas desse projeto e tem feito o governo Cardoso recuar em determinados momentos. ${ }^{17} \mathrm{O}$ que precisamos depreender disso é se o MST terá condições e capacidade para forjar um projeto político de longo prazo, capaz de aglutinar outras forças sociais comprometidas com um modelo social de caráter popular.

${ }^{17}$ Nesse sentido, "as vitórias obtidas pelo MST são inegáveis: entre 1986 e 1996, ele contribuiu para que 145 mil famílias conquistassem, via assentamento, terra no Brasil, ocupando uma área de 48.070 .172 ha. (...) O mais importante é que o ano de 1997 terminou com o balanço de duas vitórias políticas contra um governo que parecia onipotente diante das classes populares brasileiras. Uma delas é de extraordinária importância ideológica: a imensa maioria da população brasileiras tem se manifestado, inclusive por intermédio de pesquisas de opinião, inequivocamente a favor da reforma agrária”. Em segundo lugar, a Marcha Nacional por Reforma Agrária, Emprego e Justiça que garantiu espaço quase diário nos meios de comunicação. Mas, mais importante que isso, "foi a presença de grupos de caminhantes ao longo das rodovias, calçando rústicas sandálias, marchando, de vários pontos de origem, em direção à Brasília, além de inusitada, parecia quixotesca. A primeira grande pergunta era se conseguiriam chegar ao local de destino. Setores governistas apostavam que não. Como garantir assistência médica, alimentação e hospedagem ao longo do trajeto? Como garantir a disciplina de todos? Como seriam os contatos com as comunidades por onde passarian e, principalmente, onde acampassem? Cada uma dessas questões resultou em uma vitória para a marcha. (...) De sua parte, o MST, após a chegada triunfal a Brasília, teve a habilidade política de não conferir nenhuma importância especial a Cardoso. A própria audiência com o presidente da República foi considerada un evento menor" (Almeida \& Sánchez, 1998: p.83-85). 
Evidentemente que tanto o MST quanto às "puebladas", a despeito de todas as diferenças existentes entre ambos, sinalizam um extraordinário potencial de confronto com o capitalismo. As próprias "invenções democráticas"18 destes movimentos permitem pensarmos nesse sentido. As "puebladas" protagonizam um severo e generalizado questionamento das instituições formais do poder político, apresentam uma profunda desconfiança das promessas dos dirigentes políticos tradicionais e de oposição, desenvolvem alternativas políticas concretas, instituindo formas paralelas de poder, colocando em xeque as formas convencionais de representação política (Laufer \& Spiguel, 1999, p.28). As "puebladas" parecem, portanto, não se limitarem ao espontaneísmo de um movimento isolado. Elas convergem a luta de pelo menos três setores do movimento operário: ativos, desempregados e aposentados. Suas plataformas de ação são todas decididas por assembléia, portanto, garante-se a participação direta dos militantes (Laufer \& Spiguel, 1999).

${ }^{18}$ O sentido utilizado aqui não é o mesmo de Lefort (1983) enquanto confronto entre democracia e totalitarismo: 'a invenção democrática' é um acontecimento extraordinário, 'uma revolução que corre pelos séculos', instituição do político como nova instituição do social pelo fenômeno da 'desincorporação', pela perda da eficácia prática e simbólica da idéia, da imagem e do nome da unidade", conforme Chauí apresenta o seu livro (Lefort, 1983,p.11). Segundo o autor, o “ 6 dio à 'democracia burguesa' escondeu-lhes [dos 'esquerdistas'] a verdade da democracia" (1983,p.25). Assim, "é uma aberração, como escrevi em outro lugar, fazer da democracia uma criação da burguesia", mas "deveria convir que ela foi uma luta para a conquista de direitos - exatamente aqueles que se mostram hoje constitutivos da democracia" (1983,p.26). Nossa preocupação trilha outro caminho: estamos chamando de "invenções democráticas" as formas de participação, organização e decisão políticas praticadas pelas classes populares através das suas lutas sociais. Tais formas têm raízes históricas, como, por exemplo, durante a Comuna de Paris (1871) e diferem-se das formas normalmente encontradas nas democracias burguesas, substancialmente formais. Elas pressupõem, entre vários aspectos, a participação direta de todos os militantes nas tomadas de decisão e execução das tarefas. Em alguns assentamentos do MST, como o de Paranacity (PR), todos os assentados estão inseridos em algum núcleo familiar ou setor (educação, produção, saúde etc.) e, por conta disso, estão engajados em todo o processo decisório da cooperativa (COPAVI). Mensalmente realizam uma assembléia na qual podem destituir o coordenador de um núcleo ou setor, caso não encaminhe as decisões tomadas coletivamente. Além disso, qualquer cargo de direção (do "coordenador de núcleo familiar até o coordenador nacional") não garante nenhum privilégio financeiro ao eleito. 
Uma das principais características das "puebladas" são os bloqueios de vias de passagem (ruas, avenidas, auto-estradas nacionais e internacionais). ${ }^{19}$ Temos claro que "'las puebladas' estallaron a partir de urgencias reivindicativas; no se propusieron derrocar a los intendentes o gobernadores ni tomar el poder. Sin embargo, en los hechos se produjo una verdadera situación de 'acefalía' y, durante días, frente al poder de las autoridades y de las fuerzas represivas, las asambleas populares y sus representantes fueron el centro de decisión y único poder reconocido por la población que lo avaló en asambleas multitudinarias y lo respaldó frente a la represión (en Cultra Co, hasta 35.000 pobladores sobre una totalidad de 58.000 habitantes)" (Laufer \& Spiguel, 1999, p.37). O marco inicial desses protestos populares parece ser o "santiagueñazo", em 1993: "los trabajadores estatales y el pueblo de la mayores ciudades de la provincia de Santiago del Estero, cansados de un gobierno corrupto y que hacía oídos sordos a los reclamos populares, tomaron por asalto e incendiaron la Casa del Gobierno provincial, la Legislatura, los Tribunales - es decir, los tres poderes característicos de la democracia republicana - y, venciendo la resistencia de las fuerzas represivas, incendiaron también las casas de los políticos peronistas más corruptos y asediaron durante horas la del principal dirigente local del Partido Radical" (Laufer \& Spiguel, 1999, p.17).

O MST está recheado de práticas políticas inovadoras junto à sua militância. Não vamos negar que dado a dimensão nacional do movimento vamos encontrar diferenças no comportamento social, político, ideológico etc. dos militantes de acampamento para acampamento. Não podemos esperar um comportamento uniforme embasado em novos valores anticapitalistas com o mesmo grau no sertão de Pernambuco e no Pontal do Paranapanema. Entretanto, nas linhas gerais e no contato

19 Alguns dados interessantes sobre os protestos populares na Argentina: entre 1993 e 1997, registrou-se 749 "cortes de ruta". Nesse mesmo período, tivemos mais de 76 motins, ou seja, levantes populares contra instituições do governo ou do Estado. Outras formas de protesto (concentrações, boicotes, greves, greves de fome, passeatas, apagões, acampamentos, ocupações etc.) são evidentes: 1587 . Há também as greves gerais, inclusive que combinam com estas formas de protesto: foram 9 greves gerais contra a política econômica do governo ou contra algumas de suas políticas específicas (Cotarelo, 2000). 
com militantes de algumas regiões desse país, notamos que alguns princípios norteadores tentam ser aplicados e seguidos pelo conjunto dos seus membros. Assim, nas suas assembléias participam todos os acampados e/ou assentados, desde o mais jovem até o mais idoso, inclusive as mulheres: “(...) O adolescente, por exemplo, que antes era oprimido pelo pai, percebe que numa assembléia de sem-terra ele vota igual ao pai. Ele decide igual, tem o mesmo poder, tem vez e voz e se sente valorizado" (Stédile \& Fernandes, 1999, p.32).

O MST valoriza muito a disciplina entre os seus militantes. Segundo Stédile \& Fernandes, como todos ajudaram a formular as regras, estas devem ser respeitadas por todos, além do que, a adesão de qualquer militante ao movimento é por livre e espontânea vontade. Com isso, procura-se fazer com que todas as atividades dos acampamentos e/ou assentamentos estejam distribuídas entre os militantes do movimento. Todos, de uma forma ou de outra, estão inseridos em alguma comissão (infra-estrutura, higiene, negociação, saúde, educação, segurança etc.), fazendo com que se sintam importantes, úteis ao grupo e recuperem a auto-estima, tão dilapidada pelas relações sociais burguesas.

Como afirmamos no início deste artigo, procuramos analisar a "democratização" no Brasil e na Argentina articulando lutas sociais, políticas de Estado e regime político. Pudemos, sumariamente, demonstrar que as políticas de Estado desenvolvidas nos anos 90 tinham (e continuam tendo) um caráter profundamente antipopular e visavam garantir a acumulação de capital em favor do grupos locais e transnacionais. A orquestração de todo esse processo é feito a quilômetros de distância daqui, provavelmente por burocratas do FMI ou do Banco Mundial, em algum escritório em Washington ou mesmo na Casa Branca. Quando desdobramos a análise para o regime político, em face dos problemas expostos, nos deparamos com os limites estruturais da "democracia" brasileira ou argentina. Como vimos, um desses problemas, entre inúmeros outros, é que a maioria dos argentinos ou dos brasileiros não têm poder de decisão. Apenas votam. As principais decisões que determinam as políticas de Estado, como acabamos de demonstrar, são tomadas por burocratas não submetidos ao sufrágio. Reside nesse ponto uma questão grave: nos países de capitalismo dependente submissos aos ditames do capital transnacional a democracia está, no mínimo, comprometida. 
Evidentemente que esse não é o único problema das democracias latino-americanas. Deparamo-nos com outros igualmente graves: governos autoritários, repressão violenta às lutas populares, suspensão dos direitos individuais (estabelecimento do estado sítio no Paraná), criminalização dos movimentos sociais, violação dos direitos humanos, restabelecimento da famigerada "lei de segurança nacional" etc. Somente por aqui, podemos nos indagar: e as liberdades políticas, de expressão, de manifestação? Estão sendo violadas quotidianamente pelo Estado que se apresenta como "democrático de direito".

Se de um lado procuramos analisar, ainda que superficialmente, os limites estruturais da democracia e do próprio Estado burguês, por outro, tentamos observar alguns aspectos que avançam além dessa perspectiva, ou seja, as "invenções democráticas" do MST e das "puebladas". Tais movimentos apontam para a superação dos limites da democracia burguesa, procurando, até mesmo, criar condições para a gestação de novas formas de sociabilidade que sinalizam com valores anti-capitalistas. É claro que não podemos generalizar e tomar isso como regra geral de todo o movimento, tanto em relação ao MST quanto às "puebladas". Mas notamse elementos importantes, não desprezíveis, nas suas áreas de influência. $\mathrm{O}$ embate de classes e a correlação de forças em determinados momentos da história é que poderão fazê-los vingar ou não. Enquanto isso, a discussão sobre a crise de legitimidade da democracia permanece.

\section{Referências Bibliográficas}

ALMEIDA, Lúcio Flávio Rodrigues de ; SÁNCHEZ, Félix Ruiz. Um grão menos amargo das ironias da história: o MST e as lutas sociais contra o neoliberalismo". In: Revista Lutas Sociais, São Paulo, v.5, out.1998.

ANDERSON, Perry. Balanço do neoliberalismo. In: SADER, Emir; GENTILLI, Plabo (Orgs.). Pós-neoliberalismo: as políticas sociais e o Estado democrático. Rio de Janeiro: Paz e Terra, 1995.

ANTOGNAZZI, Irma. De la democracia de la burguesía nacional a la democracia de los grupos financieros transnacionales. Herramienta: revista de debate y crítica marxista, Buenos Aires, v.12, otoño 2000. 
BIONDI, Aloysio. O Brasil privatizado: um balanço do desmonte do Estado. São Paulo: Fundação Perseu Abramo, 1999.

CANO, Wilson. Soberania e política econômica na América Latina. São Paulo: Unesp, 1999.

CHOSSUDOVSKY, Michel. A globalização da pobreza: impactos das reformas do FMI e do Banco Mundial. São Paulo: Moderna, 1999.

COMPARATO, Fábio Konder. Indignidade nacional. Folha de São Paulo. São Paulo, 20 jun. 1999.

CORPORACIÓN LATINOBARÓMETRO. Sítio disponível pela Internet: Disponível em :<http://www.latinobarometro.cl $>$. Acesso em. jul. 2000.

COTARELO, María Celia. La protesta en la Argentina de los '90. Herramienta: revista de debate y crítica marxista, Buenos Aires, v.12, otoño, 2000.

DALLARI, Dalmo de Abreu. A que ponto chegamos: balanço do governo FHCardoso e perspectivas da oposição. São Paulo: Hucitec, 1998. (Estudos marxistas 6).

HARNECKER, Marta. Tornar possível o impossível: a esquerda no limiar do século XXI. São Paulo: Paz e Terra, 2000.

HUNTINGTON, Samuel P. A terceira onda: democratização no final do século XX. São Paulo: Ática, 1994.

LAUFER, Ruben; SPIGUEL, Claudio. Las 'puebladas' argentinas a partir del 'santiagueñazo de 1993. Tradición histórica y nuevas formas de lucha. In: MAYA, Margarita López. Lucha popular, democracia, neoliberalismo: protesta popular en América Latina en los años de ajuste. Caracas: Editorial Nueva Sociedad, 1999.

LEFORT, Claude. A invenção democrática: os limites da dominação totalitária. São Paulo: Brasiliense, 1983.

MOVIMENTO DOS TRABALHADORES RURAIS SEM-TERRA (MST). Disponível em: <http://www.mst.org.br>. Acesso em: 2000

O'DONNELL, Guilhermo. Contrapontos: autoritarismo e democratização. São Paulo: Vértice, 1986.

PETRAS, James. As esquerdas e as novas lutas sociais na América Latina. Revista Lutas Sociais, São Paulo, v.2, jun. 1997.

PETRAS, James. Hegemonia dos Estados Unidos no novo milênio. Petrópolis: Vozes, 2000.

PETRAS, James. Neoliberalismo: América Latina, Estados Unidos e Europa. Blumenau: FURB, 1999. 
PRZEWORSKI, Adam. Capitalismo e social-democracia. São Paulo: Companhia das Letras, 1991.

QUINTAR, Aída ; ARGUMEDO, Alcira. Argentina: os dilemas da democracia restringida. Lua Nova: revista de cultura e política, São Paulo, v.49, 2000.

REBELIÓN. Disponível em: <http://www.eurosur.org/rebelion/>. Acesso em: maio 2000.

SCRIBANO, Adrián. Argentina 'cortada': cortes de ruta y visibilidad social en el contexto del ajuste. In: MAYA, Margarita López. Lucha popular, democracia, neoliberalismo: protesta popular en América Latina en los años de ajuste. Caracas: Editorial Nueva Sociedad, 1999.

SEADE .Fundação Sistema Estadual de Análise de Dados e Estatística. Disponível em: <http://www.seade.gov.br>. Acesso em: out. 2000.

STEDILE, João Pedro ; FERNANDES, Bernardo Mançano. Brava gente: a trajetória do MST e a luta pela terra no Brasil. São Paulo: Ed. Fundação Perseu Abramo, 1999.

\section{Abstracts}

This article is a theoretical incursion about the relationships among social strife, State policies, and political regimen. The analysis favors a two-fold examination: on the one hand, the structural limitations of Brazilian and Argentinean democracies; on the other hand, the potentialities of the new 'democratic inventions', present in the demands and in the forms of organization of certain social movements through strife.

Key-1words: social strife, political crisis, legitimacy 